\title{
Trajetórias do progresso técnico na cadeia produtiva de carne de frango do Brasil
}

Carlos José Espíndola*

\section{Resumo}

Nos últimos 20 anos a produção de carne de frango no Brasil cresceu 4,5 vezes saindo de 2.358 mil ton em 1990 para 10.980 mil ton em 2010. Esta produção proporcionou um aumento do consumo per capita de 13,1 kg/hab./ano para 44,09 kg/hab./ano. No mercado externo o Brasil saiu da casa das 300 mil ton exportadas para 3.819 mil toneladas. Esse desempenho foi resultado das inovações tecnológicas introduzidas a montante (indústria fornecedora de insumos) e a jusante (logística e distribuição), bem como um amplo sistema de pesquisa, ciência e tecnologia. É, pois, neste sentido, que o texto proposto tem como objetivo identificar a trajetória do progresso técnico na cadeia produtiva de carne de frango no Brasil, com destaque para as inovações no campo da genética, da nutrição, instalação, sanidade e manejo.

Palavras-chave: Melhoramento genético; Progresso técnico; Agronegócio.

Trajectories of technical progress in the production chain of chicken meat in Brazil

\section{Abstract}

Over the past 20 years the production of chicken meat, in Brazil, has grown 4.5 times. It went from 2.358 thousand tons in 1990 to 10.98 thousand tons in 2010 . This production resulted in

* Professor do Departamento de Geociências e do PPGG - CFH/UFSC (cje@cfh.ufsc.br).

Geosul, Florianópolis, v. 27, n. 53, p 89-113, jan./jun. 2012 
ESPÍNDOLA, C.J. Trajetórias do progresso técnico na cadeia produtiva de ... the per capita increase consumption of $13.1 \mathrm{~kg} /$ inhabitant / year to $44.09 \mathrm{~kg} /$ inhabitant /year. In foreign markets, the Brazilian exports jumped from 300 thousand tons to 3.819 thousand tons. This performance resulted from technological innovations introduced in the upstream (input supply industry) and downstream (logistics and distribution) as well as a comprehensive system of research, science and technology. Therefore, the proposed text aims to identify the path of technical progress in the production chain of poultry in Brazil, with emphasis on innovations in the field of genetics, nutrition, installation, salubrity and management.

Key words: Genetic improvement; Technical Progress; Agribusiness.

\section{Introdução}

Nos anos de 1970 e 1980, emergiu na literatura acadêmica, uma série de estudos que tinham como objetivo principal demonstrar o intenso processo de modernização agrária ocorrida no Brasil. Destaca-se no desempenho da agropecuária brasileira a mecanização de processos e a intensificação do uso de insumos. Contudo, cabe destacar que o processo de mudança técnica, ocorrido na agropecuária brasileira pós metade dos anos de 1960, forjaram cadeias produtivas que intensificaram as inovações em processo e produto. A incorporação das inovações possibilitou a reabilitação da matéria viva, a melhoria nos sistemas de produção e controle, a redução dos custos de energia e matéria-prima, a diversificação da matriz energética e uma maior flexibilização do mix de produtos (elaboração de alimentos com maior valor agregado e nutricional). Por sua vez, as difusões das inovações alteraram a organização espacial, pois certas áreas do espaço geográfico podem destinar-se a produzir, outras a processar e outras a consumir, bem como, novas áreas podem ser incorporadas aos circuitos produtivos. Desta forma, a difusão de novas tecnologias afeta de forma direta "a la división espacial e internacional del 
ESPÍNDOLA, C.J. Trajetórias do progresso técnico na cadeia produtiva de ... trabajo y de la producción" (SANCHEZ, 1991, p. 263). Não se trata de um determinismo tecnológico onde as forças produtivas seriam o motor das mudanças sociais e econômicas, pois segundo Santos (1996, p. 67), a base tecnológica da sociedade e do espaço constitui, hoje, um dado fundamental da explicitação histórica, já que a técnica invadiu todos os aspectos da vida humana. A história da humanidade é inseparável da história do progresso técnico, sobretudo pelos esforços do homem em aumentar o seu domínio e controle sobre a natureza. Contudo, o progresso técnico deve ser pensado como um processo coletivo onde o ambiente institucional, econômico e natural é fundamental.

É, pois, neste sentido, que este texto visa identificar a trajetória do progresso técnico na cadeia produtiva de carne de frango do Brasil, com destaque para as inovações no campo da genética, da nutrição, instalação, sanidade e manejo.

\section{Trajetórias do progresso técnico em melhoramento genético de frango}

A carne de frango é hoje um dos principais alimentos que compõem a dieta humana. Sua importância deriva da combinação do seu preço, relativamente inferior à carne de boi e da sua máxima capacidade de transformação de cereais em carne no menor tempo possível de criação ${ }^{1}$. Este último aspecto está diretamente associado aos processos de redução da mortalidade, conversão alimentar, diminuição da idade de abate, peso médio e velocidade de crescimento, como demonstram os dados da Tabela 1.

${ }^{1}$ Em termos de consumo per capita, a carne de frango atingiu, no ano de $1995,21,8 \mathrm{~kg} / \mathrm{hab}$./ano a um preço médio de R\$ 1,75 kg. Em 2007, o consumo alcança o patamar de $38,1 \mathrm{~kg} / \mathrm{hab}$./ano a um preço de $\mathrm{R} \$ 1,16$ $\mathrm{kg}$. Em contrapartida, o consumo per capita de carne bovina decaiu de 42,6 kg/hab./ano em 1995 para 37,6 kg/hab./ano em 2007. Já seus preços decaíram de 72,59R\$/@ para 59,40R\$/@ (ANUALPEC, 2007). 
ESPÍNDOLA, C.J. Trajetórias do progresso técnico na cadeia produtiva de ...

TABELA 1: Índices de produtividade da avicultura de corte (mundo)

\begin{tabular}{|c|c|c|c|c|}
\hline Anos & $\begin{array}{c}\text { Peso vivo } \\
\text { (kg) }\end{array}$ & $\begin{array}{c}\text { Conv. } \\
\text { Alimentar } \\
\text { (kg/ração) }\end{array}$ & $\begin{array}{c}\text { Mortalida } \\
\text { de } \\
(\%)\end{array}$ & $\begin{array}{c}\text { Idade } \\
\text { (dias) }\end{array}$ \\
\hline 1925 & 1,0 & 4,7 & 1,8 & 112 \\
\hline 1945 & 1,4 & 4,0 & 10,0 & 84 \\
\hline 1965 & 1,6 & 2,4 & 6,0 & 63 \\
\hline 1985 & 1,9 & 2,0 & 5,0 & 49 \\
\hline 2005 & 2,4 & 1,7 & 4,0 & 42 \\
\hline
\end{tabular}

Fonte: The World Chicken Meat Industry, apud Avicultura Industrial n ${ }^{\circ}$, ed, 1138, 2005, elaboração do autor.

Na Tabela 1, verifica-se a redução de $4,7 \mathrm{~kg}$ de ração para cada frango vivo com idade de abate de 112 dias, em 1925, para $2,4 \mathrm{~kg}$ de ração em 42 dias, em 2005. Esse excepcional desempenho é resultado do intenso programa de melhoramento genético implantado por empresas e órgãos estatais de pesquisa.

O programa de melhoramento genético consiste na seleção (animais de uma geração que serão pais da geração subseqüente) e no cruzamento (animais pertencentes a raças ou espécies diferentes). Em um processo de melhoramento animal, a seleção e o cruzamento tendem a associar-se em busca de sinergias positiva (EUCLIDES FILHO, 1997). Em se tratando de técnicas, destacamse a Inseminação Artificial (IA); a Transferência de Embriões (TE); a micro manipulação e produção in vitro de embriões; e, mais recentemente, a clonagem e produção de animais transgênicos. Ademais, os avanços nas áreas como a tecnologia da informação (TI) aliada à crescente integração entre a genética molecular e a quantitativa abre um enorme leque de possibilidades para a melhoria das técnicas de seleção e cruzamento.

A direção do progresso tecnológico na área de melhoramento genético passou, ao longo de sua trajetória, por intenso processo de cumulatividade. Nos anos de 1920, com a constituição da American Poultry Association, foram desenvolvidas, nos EUA, pesquisas 
ESPÍNDOLA, C.J. Trajetórias do progresso técnico na cadeia produtiva de ... visando à sexagem de pintos e à extensão do conceito mandeliano de gene e das características de variação contínua. A partir de 1935, o governo norte-americano instituiu o programa de controle sanitário em aves, por intermédio do National Poultry Improvement Plan e promoveu as provas de desempenho mediante o Chicken of Tomorow. Nos anos 1960, os programas de melhoramento genético avaliaram o número de ovos incubáveis e a taxa de eclosão. Já nas décadas de 1970 e 1980, a preocupação voltou-se para a conversão alimentar. Contudo, foi a partir dos anos 1990 que as pesquisas foram direcionadas para o aumento do rendimento das partes nobres do frango e para sua capacidade de agregação de valor (PINAZZA \& ALIMANDRO, 1999) $)^{2}$.

No Brasil, Espíndola (2002) demonstrou que existiram três grandes fases no programa de melhoramento avícola no Brasil, conforme a Quadro 1.

Com base nas trajetórias apresentadas no Quadro 1, verificase que a primeira fase, período compreendido entre 1940-1960, corresponde a um intenso processo substituidor de importações por parte de instituições públicas e empresas privadas mediante a internalização de programas de melhoramento genético no Brasil visando assim à redução da dependência externa. Destaca-se, neste caso, o decreto 55.981 de 22/04/1965 que criou mecanismos para o país deixar de importar o produto final (matrizes), com fracas perspectivas para cópia e melhoramento, para importar avós.

${ }^{2} \mathrm{Na}$ linha de postura, os avanços também foram excepcionais, pois se chega a índices que ultrapassam 340 ovos em 80 semanas de idade. Isto é, mais que o dobro obtido na década de 1940, quando uma ave alojada com 70 semanas produzia 134 ovos. 
ESPÍNDOLA, C.J. Trajetórias do progresso técnico na cadeia produtiva de ...

QUADRO 1: Estruturação da Indústria de Melhoramento Genético no Brasil e Trajetória das Inovações

\begin{tabular}{|c|c|c|}
\hline Fase & Ano & Estruturação/Trajetória \\
\hline \multirow{13}{*}{ 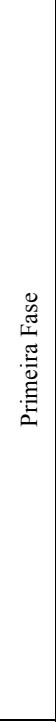 } & 1940 & - Introdução de aves da raça Leghorn no estado de São Paulo. \\
\hline & 1947 & - Comercialização de pintos da raça Hampshire pela granja Guanabara. \\
\hline & 1948 & - Programa de seleção desenvolvido pela fazenda Aves do Paraíso. \\
\hline & 1950 & $\begin{array}{l}\text { - Programa de cruzamento entre as raças Leghorn e Rodhe Island Red desenvolvido pelo Instituto de } \\
\text { Pesquisa e Experimentação Agropecuária do Centro-Sul. }\end{array}$ \\
\hline & 1951 & - Surgimento da galinha 4P (Pescoço Pelado Preta Piracicaba, criada pela ESALQ). \\
\hline & 1955 & $\begin{array}{l}\text { - Lançamento da poedeira D-55 - ave com genética própria produzida em Suzano/SP pelos } \\
\text { irmãos Doy. Em 1962, eles lançaram a D-62 que apresentava baixos índices de mortalidade } \\
\text { causada pela doença de Marck. } \\
\text { - Implantação de granjas pela Sadia e Perdigão visando ao processo de seleção e cruzamento. }\end{array}$ \\
\hline & 1957 & - Início dos trabalhos de melhoramento genético da Granja Guanabara/RJ. \\
\hline & 1960 & - Instalação da Arbor Acres/Eva em São Paulo. \\
\hline & 1962 & $\begin{array}{l}\text { - Trabalhos de cruzamento das raças Cornish Branca, New Hampshire e Plymouth Rock } \\
\text { Branca pela Estação Experimental de Pindamonhangaba/SP. } \\
\text { - Parceria entre a Granja Guanabara e a empresa canadense Shaver Poultry Breeding Farms } \\
\text { Limited. }\end{array}$ \\
\hline & 1965 & $\begin{array}{l}\text { - Proibição da importação de matrizes e obrigatoriedade da importação de avós (Dec. } \\
\text { 55.981). }\end{array}$ \\
\hline & 1966 & $\begin{array}{l}\text { - Pareceria entre a Granja Ito/SP e a empresa JJ Warren INC para a distribuição de ovos } \\
\text { vermelhos, a partir da produção de matrizes. }\end{array}$ \\
\hline & 1967 & $\bullet$ Cheg \\
\hline & 1969 & $\begin{array}{l}\text { - A empresa Hy-line Agrocomércio Ltda. passa a exportar matrizes para Assunção/Paraguai. } \\
\text { - Exportação de matrizes de postura (raça Nick-Chick) e corte (Meat Nick) pela granja H \& } \\
\text { N para a Bolívia. }\end{array}$ \\
\hline \multirow{10}{*}{ 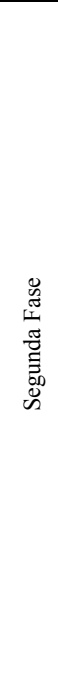 } & 1971 & $\begin{array}{l}\text { - A granja avícola de Vinhedo/SP contrata o geneticista canadense Peter A. Kondra para } \\
\text { desenvolver o Programa de Melhoramento Genético. } \\
\text { - A granja Guanabara lança três reprodutoras geneticamente brasileiras (G-190 para corte, G-307 } \\
\text { poedeira de ovos brancos e G-505 poedeira de ovos vermelhos). O Programa foi desenvolvido } \\
\text { com base nos estudos do geneticista N.R. Giles da Universidade de Arkansas/EUA. } \\
\text { - A granja Mizuma de Bastos começa a importar ovozeiras japonesas da linhagem Enya. }\end{array}$ \\
\hline & 1972 & $\begin{array}{l}\text { - A Shaver do Canadá instala-se no Brasil para, a partir da importação de ovos, abastecer o } \\
\text { mercado brasileiro. }\end{array}$ \\
\hline & 1973 & $\begin{array}{l}\text { - É criada a Big Birds, empresa responsável pela importação da linhagem de corte Ross. } \\
\text { - Instalação da Coob no Brasil. } \\
\text { - Início do Programa de Melhoramento Genético nas Universidades de São Carlos/SP, } \\
\text { Viçosa/MG, Santa Maria/RS e no Instituto de Zootecnia de Nova Odessa/SP. }\end{array}$ \\
\hline & 1976 & $\begin{array}{l}\text { - Criação da Hibrid Agroindustrial Ltda./SC. Joint Venture entre Hybrid do Canadá e a Sadia. } \\
\text { A partir dessa associação, surgiram várias empresas do Grupo Sadias especializadas no } \\
\text { Melhoramento Genético. }\end{array}$ \\
\hline & 1980 & - Lançamento da ave G-210 pela granja Guanabara. Essa ave atingia o peso de $2 \mathrm{~kg}$ em 59 dias. \\
\hline & 1981 & - A Big Birds passa a produzir no Brasil as matrizes corbett. \\
\hline & 1982 & $\begin{array}{l}\text { - A Sadia Agroindustrial passa a distribuir no Brasil aves da linhagem Pilch. } \\
\text { - Perdigão lança o Chester no mercado brasileiro. }\end{array}$ \\
\hline & 1983 & • Encerramento de operações da Companhia Genética Shaver do Brasil. \\
\hline & 1984 & - Entrada da Euribrid no Brasil por intermédio da empresa Ipê Agroavícola. \\
\hline & 1985 & $\begin{array}{l}\text { - A granja Guanabara/RJ passa a ser administrada pelo Ministério da Agricultura por meio da } \\
\text { EMBRAPA ( Centro Nacional de Pesquisa de Suínos e Aves - CNPSA). }\end{array}$ \\
\hline
\end{tabular}


ESPÍNDOLA, C.J. Trajetórias do progresso técnico na cadeia produtiva de ...

\begin{tabular}{|c|c|c|}
\hline & 1987 & $\begin{array}{l}\text { - Criação da Agroceres-Ross, uma Joint Venture entre a Agroceres e a empresa escocesa } \\
\text { Ross Breeders. }\end{array}$ \\
\hline \multirow{8}{*}{ 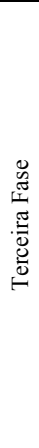 } & 1990 & - A granja Planalto fechou acordo com a Avian Farms. \\
\hline & 1994 & $\begin{array}{l}\text { - A EMBRAPA lança poedeiras de ovos brancos 031, resultado do cruzamento das linhas } \\
\text { Rhode Island Red e Plymouth Rock Branca e o frango de corte 021, resultante do } \\
\text { cruzamento entre as linhagens Plymouth Rock e Cornish Branca. }\end{array}$ \\
\hline & 1992 & $\begin{array}{l}\text { - A Sadia reduz os recursos investidos na área de melhoramento genético, eliminando suas } \\
\text { empresas agropastoris. }\end{array}$ \\
\hline & 1993 & - Eliminação de programas institucionais de melhoramento genético. \\
\hline & 1995 & $\begin{array}{l}\text { - A empresa Americana Tyson Foods, proprietária da Cobb-Vantress forma uma Joint } \\
\text { Venture com a Globoaves e Frango Sertanejo. }\end{array}$ \\
\hline & 1997 & $\begin{array}{l}\text { - As empresas Rhôde-Merieux e Merck fundiram-se e criaram a Hubbard-Isa (Institute de } \\
\text { Selections Avicole). }\end{array}$ \\
\hline & 2000 & $\begin{array}{l}\text { - A empresa Hybro By, de origem holandesa, passou a disponibilizar bisavós para o mercado } \\
\text { brasileiro. }\end{array}$ \\
\hline & 2001 & $\begin{array}{l}\text { - A Agroceres-Ross passa a importar bisavós. A Tyson Foods constrói uma granja de bisavós } \\
\text { em Paulo de Faria/SP. }\end{array}$ \\
\hline
\end{tabular}

Fonte: Adaptado de Espíndola (2002) e Edição Histórica 95 anos Gessulli Agribusiness, São Paulo: Gessulli, 2004.

Os ovozeiros são empresas que passam a importar os pintos avós ou os ovos férteis. A obtenção do pinto matriz é realizada por "intermédio do acasalamento de quatro linhagens de avós que constituem o chamado pacote de avós formado por: $100 \%$ aves fêmeas da linha fêmea, $15 \%$ aves macho da linha fêmea, $16 \%$ aves fêmeas da linha macho e $4 \%$ aves machos da linha macho. Dos acasalamentos resultam pintos matrizes, macho e fềmea da linha fềmea, que são acasalados para obtenção da matriz comercial. Os subprodutos são descartados para fins produtivos e vendidos para a produção de carne" (MENDES, 1994 apud CANEVER et al, 1997 p. 80).

A segunda fase, entre 1970-1990, configura-se como uma nova etapa do processo substituidor de importações. Esse esforço foi resultado das cumulatividades obtidas anteriormente e a introdução de novas linhagens no plantel brasileiro. Esse processo foi realizado através de pacotes abertos ou fechados. No primeiro caso há a possibilidade de se importar unicamente a linha macho ou a linha fêmea de uma determinada marca. Este é o caso da ASA alimentos que importava a linha macho Lohmann Indian River. No segundo caso o pacote é composto das duas linhas, como por exemplo, as importações realizadas pela Granja Rezende que importava a linha fêmea Hubbard e a linha macho Peterson. 
ESPÍNDOLA, C.J. Trajetórias do progresso técnico na cadeia produtiva de ... Contudo, merece destaque a importação de avós da raça Pilch, por parte da empresa Sadia, que possibilitou o rompimento com o pacote fechado da Arbor Acres que permitia apenas o cruzamento da fêmea com o macho da mesma linhagem. Assim, foi possível cruzar o macho Pilch (maior rusticidade) e a fêmea Arbor Acres (sensível a doenças), a fim de se conseguir um melhor rendimento, adaptabilidade e novas tendências de mercado (cortes).

No início dessa mesma década, o governo brasileiro resolveu que, a partir de 1975, as empresas deveriam importar avós e formar seus próprios planteis. Assim, Brasília financiou projetos nas universidades de Viçosa (MG), Santa Maria (RS), São Carlos e ESALQ-SP bem como órgãos federais (EMBRAPA). Em 1985, o governo federal adquiriu a Granja Guanabara e repassou-a à EMBRAPA, visando reforçar as pesquisas genéticas do Centro Nacional de Pesquisa de Suínos e Aves, criado em 1975, com sede em Concórdia (SC). O programa de melhoramento genético no interior do CNPSA visa criar competência nacional na formação e desenvolvimento de linhagens geneticamente superiores e comercialmente competitivas para a produção de carne e ovos (SCHMIDT, 1991). Portanto, o país poderia sair da condição de imitador retardatário para imitador com grande capacidade de inovação. Isto é, para uma forma superior de dependência (RANGEL, 1982).

A Perdigão, por seu turno, foi capaz de gerar um banco genético próprio: o chéster, resultado da combinação de sete raças puras importadas dos EUA, em 1979. O Grupo Perdigão possuía uma unidade de pesquisa genética em Rio Claro (SP), com a participação de 30\% da empresa norte-americana Cobb Venture. Já o grupo Sadia, através de uma joint venture com o grupo canadense Hybrid, passou a controlar a importação de avós de perus ${ }^{3}$. Dessa

${ }^{3}$ O Grupo Sadia, representante das linhagens norte-americanas Pilch e Arbor Acres, prefere continuar importando as avós, por duas razões: $1^{\mathrm{a}}$ ) porque os avanços tecnológicos são muito rápidos e os avicultores brasileiros necessitam de melhor potencial genético para manter a 
ESPÍNDOLA, C.J. Trajetórias do progresso técnico na cadeia produtiva de ... associação criou-se, em 1976, a Hybrid Agropastoril Ltda., com sede em Chapecó, nas dependências da unidade industrial do grupo Sadia nessa cidade. Essa associação possibilitou a formação e o desenvolvimento de várias unidades especializadas no melhoramento genético: Sadia Agropastoril Paranaense Ltda., Sadia Agropecuária Ltda., Sadia Catarinense Ltda. e Sadia Agropastoril Goiás Ltda.

A terceira fase, pós 1990, caracteriza-se pelo intenso processo de entrada de grandes empresas multinacionais, o desaparecimento de outras e a redução dos investimentos por parte de instituições públicas e de empresas privadas nos programas de melhoramento genético no Brasil ${ }^{4}$. Segundo Rizzi (1993), a falta de investimentos pode ser assim explicitada: (a) a dificuldade de as empresas alcançarem o estágio tecnológico das linhagens importadas; (b) o investimento é de alto risco e de longa maturação e (c) a quase impossibilidade do descobrimento de raças puras. Entretanto, cabe destacar que o problema de desenvolvimento de linhagens nacionais não é uma dificuldade de capacitação técnica nem de material genético. O problema é o esforço financeiro que é diluído num universo maior (ARTUR, 1991). Dessa maneira, quando o governo federal funcionava como aparato financeiro, foi possível às empresas visualizarem as oportunidades para investimentos em pesquisa genética. Para o grupo Sadia, a paralisação dos investimentos foi uma estratégia utilizada para reavaliar os programas de melhoramento genético em função da

competitividade da produção; $2^{\mathrm{a}}$ ) porque, em função da alta capacidade reprodutiva das avós (uma fêmea avó importada representa uma produção superior a $12.000 \mathrm{Kg}$ de frango), a influência do custo das importações sobre o custo final é muito pequena. A relação custo/benefício é, portanto, amplamente favorável (Espindola 2002).

${ }^{4}$ Em 2006, existiam poucas empresas que oligopolizam o setor genético de frango de cortes. Dentre elas destaca-se Agroceres-ROSS (Escócia), Arbor Acres (EUA), Hubro (Holanda), Hubbard Peterson (Canadá), Cobb (EUA), ISA (França) e Avian Farms (EUA). 
ESPÍNDOLA, C.J. Trajetórias do progresso técnico na cadeia produtiva de ... entrada de grandes corporações internacionais no mercado brasileiro de genética avícola.

A inserção das corporações internacionais no mercado brasileiro decorre da falta de oportunidades dentro dos seus mercados tradicionais e a interna competição inter capitais. A Agroceres, por exemplo, após associar-se a Ross British International, passou a importar bisavós que foram fornecidas para a Sadia, Frangosul, Avipal e Pena Branca. Com isso, a participação da Agroceres no mercado interno subiu de 12\% em 1991 para $42,9 \%$ em 1999. Com isso, a norte-americana Cobb Vantress, subsidiária da Tyson Foods, direcionou em 2001, US\$ 10 milhões na construção de aviários destinados à produção de bisavós no Brasil. A terceira granja da empresa (as outras duas estão localizadas nos EUA e Inglaterra) serve de base exportadora de aves melhoradas geneticamente para toda a América do Sul e parte da Ásia (ESPÍNDOLA, 2002).

Quanto às novas perspectivas para a área de melhoramento genético, vale ressaltar que a trajetória do progresso técnico caminhará, por um lado, na direção do aprofundamento da busca do genoma da galinha e do seu possível mapeamento. A técnica do mapeamento tem o objetivo de especificar os Loci de Características Quantitativas (QTL). Em termos gerais, pode-se afirmar que o melhoramento genético em frango de corte estará centrado na melhora genética contínua das características e na maximização da produção de carne de alta qualidade com o mínimo de custos produtivos.

\section{Trajetórias do progresso técnico na área de nutrição}

A nutrição desempenhou um papel decisivo no desenvolvimento da agropecuária nacional. Entre 1971 e 2006, a produção brasileira de ração cresceu de 3,3 milhões de toneladas para 51,3 milhões de toneladas. A indústria de nutrição - composta pelo segmento de rações, segmento de suplementos e de micronutrientes - surgiu inicialmente em 1940 nos estados de São 
ESPÍNDOLA, C.J. Trajetórias do progresso técnico na cadeia produtiva de ... Paulo e Rio de Janeiro, com o aproveitamento dos resíduos do setor moageiro de trigo, objetivando o abastecimento da bovinocultura leiteira. Na década de 1960, o governo brasileiro criou programas creditícios que ofereciam subsídios à implantação de indústrias de ração no país, visando à expansão da capacidade de produção interna, conforme pode ser verificado no Quadro 2.

QUADRO 2: Estruturação da indústria de nutrição e trajetória das inovações

\begin{tabular}{|c|l|}
\hline Ano & \multicolumn{1}{c|}{ Estruturação/Trajetória } \\
\hline 1920 & $\bullet$ Utilização da farinha de osso para o alimento das aves. \\
\hline 1930 & $\begin{array}{l}\text { • Redirecionamento da nutrição animal com a adição de vitaminas à ração, } \\
\text { proporcionando aquecimento e proteção contra as moléstias transmissíveis. }\end{array}$ \\
\hline 1951 & $\begin{array}{l}\text { • Produtores avícolas solicitam ao Ministério da Agricultura permissão para } \\
\text { importação de farinha de carne. }\end{array}$ \\
\hline 1954 & $\bullet$ Desenvolvimento nos EUA da vitamina B12 pela empresa Cronomid. \\
\hline 1960 & • Introdução do cálcio nas rações. \\
\hline 1965 & $\begin{array}{l}\text { • Promulgação da Lei 4.736, de 15/07/1965, que regulamentava a produção de } \\
\text { ração no Brasil. }\end{array}$ \\
\hline 1967 & $\bullet$ Instalação da Purina no município de Campinas/SP. \\
\hline 1970 & $\bullet$ Cargill instala em Araraquara/SP fábrica de rações. \\
\hline 1972 & $\bullet$ Roche inaugura em São Paulo fábrica de vitaminas e premix. \\
\hline 1975 & $\bullet$ Reconhecimento da importância dos aminoácidos na elaboração das rações. \\
\hline 1976 & $\bullet$ Nova lei de fiscalização das fábricas de ração - Lei 6.198, de 7/01/76. \\
\hline 1980 & $\bullet$ A empresa Supre Mais exporta 30 toneladas de Premix para a Bolívia. \\
\hline 1981 & $\bullet$ A empresa Minuano inaugura em Arroio do Meio/RS fábrica de rações. \\
\hline 1986 & $\bullet$ Nasce o Colégio Brasileiro de Nutrição Animal. \\
\hline 1991 & $\bullet$ A Basf entra no mercado de Premix. \\
\hline
\end{tabular}

Fonte: Adaptado de Espíndola (2002) e Edição Histórica 95 anos Gessulli Agribusiness, São Paulo: Gessulli, 2004.

Destaca-se no quadro 2 a promulgação da Lei 4.736 de $15 / 07 / 1965$, que passa a regulamentar a produção de ração no Brasil. Contudo, foi com a verticalização do sistema de criação de aves e suínos implantados pelas agroindústrias do oeste catarinense pós $1950^{5}$, que a produção de ração apresentou um crescimento

${ }^{5}$ O sistema de integração foi implantado em Concórdia, a partir dos anos de 1950, pela empresa Sadia, e disseminada para outras áreas do 
ESPÍNDOLA, C.J. Trajetórias do progresso técnico na cadeia produtiva de ... superior a 15 milhões de toneladas (PINAZZA e ALIMANDRO, $1999)^{6}$.

Na composição da ração para frango de corte, os elementos macronutrientes que advêm do milho, farelo de soja, sorgo, triquilho, sal, farinha de carne, farinha de osso, fosfatos, calcário e de outros ingredientes representam $98,8 \%$ do volume total da ração. Desse total, o milho representa $70 \%$ do custo da produção. O restante é formado pelos micronutrientes como vitaminas, microminerais, aminoácidos e outros aditivos.

Em função da possibilidade de uma crise na oferta de milho ${ }^{7}$, somada ao desenvolvimento de novos ingredientes, a necessidade de eficiência alimentar e qualidade da carne, as

território catarinense pela Secretaria da Agricultura, ACARESC, Associações Rurais e agroindústrias. O sistema consiste em uma relação contratual entre a agroindústria e o produtor, em que a empresa garante a compra de toda a produção, fornecendo ao produtor a assistência técnica e parte dos insumos. A adoção do sistema de integração faz parte do projeto modernizante da agricultura, com o objetivo explícito de aumento da produção, da produtividade agrícola, novas relações de produção, dissolução da estrutura produtiva rural autossuficiente, mediante a utilização de métodos, técnicas, equipamentos e insumos modernos. Isto é, aumento considerável da composição orgânica do capital (ESPÍNDOLA, 1999). Portanto, esse sistema precoce difere das formulações de Sorj et al. (1982) que segundo os autores o sistema se originou na década de 60 . Na verdade, os anos de 1960 caracterizam-se pela expansão do sistema.

${ }^{6}$ Em 1980, existiam mais de quarenta empresas atuantes na produção de rações, com destaque para a Agroceres, Anderson Clayton, Cargill, dentre outras. Hoje, o mercado é dominado pela Nutron, Nutrix, Agroceres, Fatec, Nutrimix e Super - segmento de rações -; Tortuga, Manah, Mitsui, Novamix, Nutrisul - segmento de suplementos.

${ }^{7}$ A crise pode ocorrer em função da utilização das áreas de cultivo do milho por parte dos produtores de soja que estão com o seu produto valorizado no mercado externo, bem como a expansão da cana-deaçucar para a região Centro-oeste brasileira. 
ESPÍNDOLA, C.J. Trajetórias do progresso técnico na cadeia produtiva de ... empresas têm buscado matérias-primas alternativas, como o grão da soja processado, o triticale, a quinoa e o extrato de sopanimas.

Além do macro nutriente alternativo, um novo micro nutriente está sendo desenvolvido por empresas especializadas a fim de contribuir para uma melhor conversão alimentar. Nesse processo, merecem destaque os probióticos, prebióticos, enzimas, ácidos orgânicos, fitoterápicos, ácidos graxos e o butirato de sódio (MARQUES, 2002). A Rovimix, por exemplo, desenvolveu um suplemento alimentar à base de vitamina $\mathrm{D}$ que maximiza $\mathrm{o}$ desenvolvimento ósseo e a qualidade do sêmem em machos.

Entretanto, desde a expansão considerável da produção de frango pós 1990, tem sido comum atribuir e associar esse crescimento ao uso de hormônios nas rações utilizadas ${ }^{9}$. Na verdade, não se trata de hormônios, mas sim de antibióticos que agem diretamente na microbiota do trato digestivo. Os antimicrobianos promotores de crescimento (APC) estão, desde o final dos anos 1970, sendo questionados, pois o seu uso contínuo possibilitou a criação de bactérias resistentes a esses antibióticos. Assim, em 1999, a Comunidade Européia baniu o uso de tilosina, virgianomicina e bacitrocina de zinco como APCs; a proibição total do uso de APC ocorreu em 2006 (FIORENTIN, 2005). Essa nova regulamentação, estabelecida pela Comunidade Européia, está forçando a indústria de nutrição animal a buscar novos micronutrientes (enzimas e probióticos).

${ }^{8} \mathrm{O}$ triticale é um híbrido de trigo e centeio desenvolvido para conter alto nível de proteína, elevado conteúdo energético e alta produtividade. A quinoa é originária dos Andes e possui valores de gordura e proteína superiores ao milho e ao trigo. O extrato vegetal de sopanimas reduz o nitrogênio e fósforo na cama do aviário do frango.

${ }^{9}$ A produção mundial de carne de frango cresceu de 27.413 mil toneladas em 1990 para 75.991 mil toneladas em 2010. Neste período, a produção brasileira cresceu $8,6 \%$ para $14,4 \%$ enquanto a produção Européia decresceu de $17 \%$ para $11,56 \%$ no mesmo período. 
ESPÍNDOLA, C.J. Trajetórias do progresso técnico na cadeia produtiva de ...

\section{Trajetória do progresso técnico na área de sanidade}

$\mathrm{Na}$ atual estrutura da avicultura brasileira, a indústria de produtos veterinários tornou-se indispensável à produção de animais cada vez mais produtivos e livres de doenças e contaminações. $\mathrm{O}$ segmento de produtos veterinários é composto hoje por um total de 85 empresas, com a liderança da Tortuga com $19 \%$, seguida da MS.Dagvet, Pfizer, Rhodia, Hoechst, Bayer, Giba Geigy, Valleé, Solvay, Fatec, e outras ${ }^{10}$.

O Quadro 3 demonstra sinteticamente a estruturação da indústria veterinária no Brasil e as principais inovações tecnológicas.

A análise do Quadro 3 demonstra que, apesar do domínio das empresas multinacionais, ocorreu um esforço de empresas nacionais (Tortuga e Fatec) em desenvolverem ou importarem vacinas para a melhoria da sanidade do rebanho avícola brasileiro. Verifica-se ainda que, a partir de 1993, houve um intenso processo de fusão e aquisição empresarial.

Em termos de inovações recentes, pode-se destacar o desenvolvimento nos EUA, a partir de 1982, de uma máquina vacinadora com capacidade para 75 mil aves em 7 minutos, utilizando apenas dois trabalhadores enquanto no sistema de vacinação nos pintos o tempo é de 45 minutos ocupando cinco trabalhadores. No Brasil, essa tecnologia chegou em 2000 e, em $2005,85 \%$ das reprodutoras e $32 \%$ dos frangos de corte já utilizavam essa nova tecnologia (Avicultura Industrial, $n^{\circ} 4,2005$ ).

${ }^{10}$ Em 1990, existiam um total de 89 laboratórios empregando cerca de 10 mil pessoas. Em 1995, o faturamento da indústria de produtos veterinários registrou um valor de US\$ 750 milhões o que coloca o país como terceiro mercado mundial, atrás dos EUA e França (CANEVER et al, 1997). 
ESPÍNDOLA, C.J. Trajetórias do progresso técnico na cadeia produtiva de ... QUADRO 3: Estruturação industrial e trajetória das principais inovações no mercado de saúde avícola

\begin{tabular}{|c|c|}
\hline Ano & Estruturação/Trajetória \\
\hline Dec. 1940 & $\begin{array}{l}\text { - Instalação das primeiras multinacionais no Brasil. } \\
\text { - Criação do Instituto Biológico de São Paulo e do Instituto Oswaldo Cruz/RJ. }\end{array}$ \\
\hline 1952 & $\begin{array}{l}\text { - Instalação da Pfizer no Brasil, com a construção de sua fábrica em } \\
\text { Guarulhos/SP. }\end{array}$ \\
\hline 1954 & • Fundação da Tortuga e o lançamento de minerais iodados e polivitamínicos. \\
\hline 1957 & - Instalação do Laboratório Bio-vet em São Paulo. \\
\hline 1960 & $\begin{array}{l}\text { - A Dow Chemical Inter-American lança a Zoamix - produto para controle da } \\
\text { coccidiose. } \\
\text { - A Associação Nacional de Ciências Avícolas dos EUA lança a vacina contra a } \\
\text { cólera avícola. }\end{array}$ \\
\hline 1965 & $\begin{array}{l}\text { - Lançamento de novo equipamento para a vacinação contra a doença de } \\
\text { Newcastle. }\end{array}$ \\
\hline 1966 & $\begin{array}{l}\text { - Fundação da Empresa Fatec e a criação da Rhodia Merieux Veterinária em } \\
\text { Recife. }\end{array}$ \\
\hline 1971 & $\begin{array}{l}\text { - Importação de vacinas contra a doença de MARECK. } \\
\text { - A Fatec importa do Japão vacinas contra coriza. }\end{array}$ \\
\hline 1972 & - A Marivax-Cooper lança a vacina Liopilizada contra a doença de MARCK. \\
\hline 1974 & - A Pfizer passa a desenvolver no Brasil a vacina contra a doença de Newcastle. \\
\hline 1981 & $\begin{array}{l}\text { - Criação da Intevet. } \\
\text { - Criação da Unidade Rhodia Nutrição Animal. }\end{array}$ \\
\hline 1984 & - A Rhodia-Mérieux nacionaliza a produção de vacinas contra a coriza. \\
\hline 1987 & • Instalação do Laboratório Virbac. \\
\hline 1993 & $\begin{array}{l}\text { - Parceria Pfizer e USP para o desenvolvimento de um mapa nacional de } \\
\text { incidência da bactéria Escherichia Coli. }\end{array}$ \\
\hline 1995 & - A Rhôme-Mérieux e a Merck \& Co uniram-se para criar a Merial. \\
\hline 1999 & $\begin{array}{l}\text { - Criação da Aventis Animal Nutrition. Essa empresa é resultado da fusão dos } \\
\text { grupos Rhône-Poulenc e Hoechst A.G. }\end{array}$ \\
\hline 2002 & $\begin{array}{l}\text { - A Schering-Plough foi adquirida pela Coopers Brasil Ltda., formando assim a } \\
\text { Schering Plough Coopers. } \\
\text { - O Ministério da Agricultura inicia o mapeamento da doença de Newcastle no } \\
\text { Brasil. }\end{array}$ \\
\hline 2005 & $\begin{array}{l}\text { - A Phytosythése (empresa francesa) desenvolveu um produto que combate o } \\
\text { surgimento e proliferação de bactérias. Esse produto visa substituir os } \\
\text { antibióticos promotores do crescimento. }\end{array}$ \\
\hline
\end{tabular}

Fonte: Adaptado de Espíndola (2002) e Edição Histórica 95 anos Gessulli Agribusiness, São Paulo: Gessulli, 2004.

Essa inovação fez emergir um novo processo de identificação e separação por sexo na fase de pré-eclosão. $\mathrm{O}$ 
ESPÍNDOLA, C.J. Trajetórias do progresso técnico na cadeia produtiva de ... processo envolve a abertura de um orifício na porção lateral do ovo aos 15, 16 e 17 dias de incubação e de um segundo orifício em sua parte superior para a vacinação em ovo aos 18 ou 19 dias de incubação ${ }^{11}$. Portanto, pode-se concluir que, no segmento de sanidade, as perspectivas para novas tecnologias estão sendo aceleradas visando à melhora da saúde das aves. Contudo, o lançamento de novos produtos com novos princípios ativos é realizado principalmente no exterior (nos grandes laboratórios internacionais) e, posteriormente, repassado para o mercado mundial por meio de suas próprias filiais (CANEVER et al, 1997).

\section{Trajetória do progresso técnico no segmento dos equipamentos avícolas}

Além dos segmentos de melhoramento genético, nutrição e sanidade contribuírem para o excelente desempenho da avicultura brasileira, é mister ressaltar a importância dos equipamentos instalados visando também à redução dos custos e ao aumento do bem-estar das aves. Assim, a indústria de equipamentos avícola veio "pari passo" implantando uma gama de inovações em processos e produtos que, associados às estratégias de manejo, objetivam o aumento da produtividade. O Quadro 4 apresenta os principais movimentos ocorridos na indústria de equipamentos.

Com base no quadro 4 , pode-se verificar que: (1) durante os anos 1960 e 1970, houve um esforço nacional na internalização da indústria de equipamentos avícolas, rompendo com isso a importação; (2) algumas empresas surgiram da inversão de capitais da área de nutrição para os segmentos dos equipamentos; (3) as empresas nacionais saíram da simples condição de produtores imitadores para criadores de tecnologia; (4) o abastecimento do

${ }^{11}$ A identificação automatizada de pintos machos na pré-eclosão consiste da detecção de composto estrogênico presente no líquido alantóide de embriões femininos, mas não em masculinos. Essa tecnologia poderá substituir o processo de sexagem criado pelos japoneses por meio da observação da cloaca do pinto. 
ESPÍNDOLA, C.J. Trajetórias do progresso técnico na cadeia produtiva de ... mercado interno caminhava conjuntamente com o abastecimento do mercado externo (América Latina, EUA e África); (5) a abertura comercial da década de 1990 promoveu uma desnacionalização ou dumping neste segmento industrial. $\mathrm{Na}$ verdade, no segmento de equipamentos, o mercado está altamente concentrado nas mãos da Anglia Auto Flow, Big Dutchmam, Casp, Corti/Avioeste, Desatron internacional, GSI/Agromarau, Nuters Brasil, Plasson, Tesnoesse e Valco (ESPÍNDOLA, 2002).

QUADRO 4: Estruturação da indústria de equipamentos e as inovações tecnológicas

\begin{tabular}{|c|c|}
\hline Ano & Estruturação/Trajetória \\
\hline 1931 & $\begin{array}{l}\text { - Utilização de baterias para criação de pintos. As baterias eram produzidas pela } \\
\text { empresa DOVE de Bragança Paulista e a MJ Michelotti de São Paulo. }\end{array}$ \\
\hline 1936 & - Nascimento da CASP e importação das incubadoras Chick Master dos EUA. \\
\hline 1953 & - Utilização de baterias na criação de galinhas poedeiras. \\
\hline 1960 & $\begin{array}{l}\text { - Lançamento do comedouro automático caseiro. } \\
\text { - Inicia-se nacionalmente a produção das incubadoras com nível técnico } \\
\text { comparável aos equipamentos importados. }\end{array}$ \\
\hline 1969 & - A CASP inicia a produção de bebedouros e comedouros automáticos. \\
\hline 1970 & $\begin{array}{l}\text { - Começam a ser desenvolvidos nos EUA e Canadá os bebedouros de baixa } \\
\text { pressão. Os de caneca e de bico ou Nipple que reduz a mão-de-obra } \\
\text { empregada e economiza água. }\end{array}$ \\
\hline 1973 & - A empresa Lucato \& Cia. exporta equipamentos avícolas para a Bolívia. \\
\hline 1980 & $\begin{array}{l}\text { - A Supre Mais lançou no mercado o comedouro bandeja que propicia menos } \\
\text { desperdício e mais higienização. } \\
\text { - A CASP lançou a maior incubadora do mundo (CM 150). } \\
\text { - A Instalaços e Máquinas para a Avicultura (IMAVI) inicia a exportação de } \\
\text { equipamentos para o Paraguai. }\end{array}$ \\
\hline 1982 & - A CASP inicia suas exportações para os EUA. \\
\hline 1983 & $\begin{array}{l}\text { - A Lucato inicia suas exportações para a Nigéria, em função da construção, } \\
\text { pela Unibras Farms, de um dos mais modernos complexos avícolas do mundo. } \\
\text { - Instalação de computadores na atividade avícola. }\end{array}$ \\
\hline 1987 & - Introdução de sistemas de informatização no incubatório. \\
\hline 1990 & a importação de equipamentos. \\
\hline 1998 & - Agromarau foi adquirida pelo Grupo GSI. \\
\hline 2000 & - Big Dutchman adquiriu a Avimec de Caxias do Sul. \\
\hline 2001 & $\begin{array}{l}\text { - A União Européia criou um novo sistema de gaiolas para as aves poedeiras. } \\
\text { Nelas, as aves estão livres para circular pelo galinheiro. }\end{array}$ \\
\hline
\end{tabular}

Fonte: Adaptado de Espíndola (2002) e de Edição Histórica 95 anos Gessulli Agribusiness, São Paulo: Gessulli, 2004. 
ESPÍNDOLA, C.J. Trajetórias do progresso técnico na cadeia produtiva de ...

As inovações ocorreram igualmente em relação às instalações, pois, na produção de frango, o meio ambiente exerce influência sobre os resultados zootécnicos. Assim, para controlar as condições adversas do clima, a indústria avícola utiliza equipamentos de climatização do aviário como ventiladores, umificadores, aquecedores, cortinas isolantes ou sistema de túnel ${ }^{12}$. O sistema de resfriamento adiabático evaporativo consiste em alterar o ponto de estado psicométrico do ar, para maior umidade e menor temperatura, mediante o controle do ar com a superfície umedecida ou líquida, ou com água aspergida ou pulverizada.

O sistema de túnel de ventilação tem a finalidade de remover o ar em toda a extensão do aviário. A utilização do sistema de túnel de ventilação em aviários em Santa Catarina (Concórdia) reduziu de 2 a 5 pontos percentuais a mortalidade dos frangos. Isto é, produtores que perdiam de 30 a 70 mil frangos, durante a pressão do calor (outubro-dezembro), reduziram a perda para 3 a 10 mil frangos (PATRICIO, 2003) ${ }^{13}$. Essas perdas na produção do frango durante a época de calor podem representar um custo a mais da ordem de 0,17 centavos por frango. Num galpão tradicional de 1.200 metros quadrados, onde são alojados 15 mil frangos, pode-se perder mais de R $\$ 2.000,00$ por lote. Dessa

12 Os convencionais são de tamanho variado, normalmente de $100 \mathrm{~m}$ de comprimento por $12 \mathrm{~m}$ de largura, com capacidade de alojamento de 12 frangos por $\mathrm{m}^{2}$. Todo o sistema de alimentação e de tratamento é manual ou automático (campânulas de gás, bebedouros do tipo nipple ou pendulares, ventiladores e nebulizadores manuais). Os semi-climatizados são de $125 \mathrm{~m}$ por $12 \mathrm{~m}$ de largura e com capacidade de alojar 14,5 aves por $\mathrm{m}^{2}$. O sistema de alimentação é automático e a climatização do ambiente é mais sofisticada. Os climatizados são acima de $125 \mathrm{~m}$ de comprimento por $12,5 \mathrm{~m}$ de largura com capacidade para 17 a 20 aves por $\mathrm{m}^{2}$. A estrutura é de concreto e totalmente fechada por cortinas especiais que evitam a absorção do calor.

13 A introdução do sistema climatizado automatizado permite que um trabalhador cuide de até três barracões de aves. Nos convencionais, um trabalhador pode cuidar de apenas dois aviários. 
ESPÍNDOLA, C.J. Trajetórias do progresso técnico na cadeia produtiva de ... maneira, uma empresa que produza 50 milhões de frangos nos sete meses de calor pode perder mais de R\$ 8 milhões (PATRÍCIO, 2003). Já para manter a temperatura ambiente dentro da região de conforto térmico das aves, existem o aquecimento central e o aquecimento local - baseado no aquecimento somente da superfície do local onde se alojam os pintos, em relação ao aviário $^{14}$. Em ambos os sistemas, são comuns o uso de sobre cortinas fixadas na parte interna do aviário. As sobre cortinas são usadas nos primeiros dias das aves para auxiliar as cortinas, evitando a entrada de correntes de calor.

Em sua maioria, esses sistemas são controlados por softwares de gerenciamento e planejamento. De acordo com Marmentin (2003), é só deixar todo o sistema programado que os exaustores ligam e desligam automaticamente quando necessário. A ração é fornecida de forma automática e as cortinas obedecem a um sensor de temperatura que as levantam ou as abaixam conforme programado $^{15}$.

${ }^{14}$ Este sistema consiste no aquecimento homogêneo de todo o aviário. Para reduzir o volume de ar a ser aquecido, é providenciado o alojamento de $2 / 3$ do aviário por meio de divisórias de lona plástica e de forro. Utilizam-se ainda campânulas com fontes de aquecimento a carvão. O sistema de aquecimento local é muito utilizado nos aviários convencionais. Para melhorar a eficiência do sistema, é comum a utilização de estufas ou forros com uso de círculos de proteção, cuja finalidade é proteger as aves de correntes de ar e demarcar a área a ser aquecida. Dentre os tipos de aquecedores, podem-se destacar os a lenha (campânulas e fornalhas), elétricos (campânulas elétricas, lâmpadas infravermelhas e resistência embutida no piso), a gás (campânulas de gás, cerâmica e infravermelha, e geradores de ar quente) e os alternativos (biogás, canalização de água quente no piso e aquecimento solar). Os biodigestores, por exemplo, podem utilizar a cama do aviário (ABREU, 2002).

15 Entrevista concedida por Rodrigo Marmentin (avicultor de Cascavel/PR) à revista Avicultura Industrial, nº 03, 2003. 
ESPÍNDOLA, C.J. Trajetórias do progresso técnico na cadeia produtiva de ...

A programação e o controle do bem-estar das aves, via aviários climatizados, redefiniram os padrões dimensionais dos aviários de 100 metros de comprimento por 12 metros de largura e de $50 \mathrm{~m}$ comprimento/10 $\mathrm{m}$ de largura, para aviários com $125 \mathrm{~m}$ de comprimento por $12,5 \mathrm{~m}$ de largura que possibilitaram uma maior densidade de aves por metro quadrado. Os aviários que antes alojavam 12.800 aves passam a alojar mais de 25 mil aves, podendo atingir 100 mil aves.

Entretanto, o elevado custo na introdução desses equipamentos tem reprimido alguns investimentos ${ }^{16}$. Com isso, não se encontra no Brasil um padrão de aviário climatizado. Existem regiões como o Centro-Oeste, por exemplo, onde já se verifica a utilização de aviários com túnel de ventilação, nebulizadores de água e sistema de recirculação de água em painéis de evaporação. Nas regiões Sul e Sudeste, a tendência é a de adaptações (melhorias contínuas) nos aviários convencionais e semiautomatizados, que têm conseguido atender às necessidades de conforto térmico das aves.

As inovações realizadas no segmento de melhoramento genético, nutrição, sanidade e equipamentos receberam o apoio do programa de rastreabilidade. Esse programa consiste na obtenção de dados, desde a origem da ração, pintinhos e medicamentos até o produto final. O seu resultado é apresentado ao consumidor por um selo com uma etiqueta numérica que permite estabelecer todas as fases de produção ${ }^{17}$.

16 Para a construção de um aviário climatizado de $100 \mathrm{~m} \mathrm{x} \mathrm{12,5} \mathrm{m,}$ estima-se um custo total de 80 mil reais, contra 64 dos aviários semiclimatizados e 30 mil dos convencionais.

${ }^{17}$ Nos últimos anos, emergiram, na indústria avícola mundial, discussões referentes à qualidade e à quantidade dos produtos. Essas discussões foram influenciadas pela intoxicação de salmonella na Inglaterra (1955), pela doença da vaca louca na Europa (1996) e pelos resíduos de antibióticos em salsichas na Alemanha (2001). 
ESPÍNDOLA, C.J. Trajetórias do progresso técnico na cadeia produtiva de ...

\section{Considerações finais}

Em termos gerais, pode-se afirmar que os avanços da avicultura brasileira foram resultados da introdução de inovações nas áreas de genética, nutrição, sanidade e novos equipamentos no sistema criatório. Isso possibilitou, a exemplo da avicultura dos países desenvolvidos, um ganho significativo na taxa de conversão alimentar. Pois, se no início dos anos 1970, os frangos brasileiros eram abatidos com 60 dias, atualmente, são abatidos em 42 dias, pesando $1,680 \mathrm{~kg}$ cada um.

Em todas as áreas, verificou-se, até final da década de 1980, um esforço das empresas brasileiras e instituições públicas em fortalecer atividades internas para o desenvolvimento de capacidade tecnológica. Tratou-se inicialmente da aquisição de tecnologia em estado puro, via pacotes tecnológicos. Num segundo momento, esses pacotes eram assimilados e aperfeiçoados, promovendo, dessa forma, pequenos melhoramentos. Portanto, houve um intenso processo de aprendizado pela prática que resultou inovações em processo e produto.

A capacidade de aprendizado tecnológico foi ainda impulsionada pela assimilação do conhecimento existente, do conhecimento tácito, da regulação estatal e dos incentivos governamentais. Sendo assim, pode-se afirmar que o Brasil direcionava-se para um processo de catching up. Isto é, um estágio superior de dependência. Pois, o subdesenvolvimento deve ser visto de forma relativa, "não comparativamente a outro país qualquer, mas sim a um estágio superior do seu próprio desenvolvimento" (RANGEL, 1982 p. 27).

Entretanto, a contra-revolução, iniciada em 1990, promoveu uma intensa desnacionalização de vários segmentos industriais atuantes na cadeia produtiva avícola. Ou seja, a transferência de tecnologia fez-se a partir de investimento externo direto e/ou por meio de representantes dos grandes oligopólios multinacionais. Nesse sentido, as empresas brasileiras adotaram estratégias que reduziram os processos imitativos e ampliaram o atraso, pois 
ESPÍNDOLA, C.J. Trajetórias do progresso técnico na cadeia produtiva de ... passaram novamente a adquirir pacotes tecnológicos fechados. Por outro lado, o Estado reduziu os incentivos governamentais e não propiciou a possibilidade de criação de um Sistema Nacional de Inovação capaz de acelerar o catching up.

\section{Referências bibliográficas}

ABREU, P.G. e ABREU, V.M.N. Conforto térmico. In: Avicultura Industrial n ${ }^{\mathbf{4}}$. Gessulli, 2002.

ABREU, Valéria. Produtividade e bem-estar. In: Avicultura Industrial no 8. São Paulo: Gessulli, 2002.

ANTUNES, R. O dilema da climatização. In: Avicultura Industrial, $\mathbf{n}^{\mathbf{0}}$ 6. São Paulo: Gessuli, 2005.

ARTUR, D.J. Avicultura, Suinocultura e Industrialização de Carnes - Anuário. São Paulo: Gessulli, 1991.

Avicultura Industrial $n^{\circ}$ 6, ano 93, ed. 1102. São Paulo: Gessulli, 2002.

Avicultura Industrial no 9, ed. 1138. São Paulo: Gessulli, 2005.

CAMPOS, Egladson J. A Biotecnologia no Melhoramento Genético. In: Avicultura, Suinocultura e Industrialização de Carnes - Anuário. São Paulo: Gessulli, 1991.

CANEVER, M.D. et al. A Cadeia produtiva de frango de corte no Brasil e na Argentina. Concórdia: EMBRAPA-CNPSA, 1997.

DELGADO, Guilherme da C. Capital financeiro e agricultura no Brasil 1969-1985. Campinas: UNICAMP, 1985.

Edição Histórica 95 anos Gessulli Agribusiness. São Paulo: Gessulli, 2004. 
ESPÍNDOLA, C.J. Trajetórias do progresso técnico na cadeia produtiva de ... ESPÍNDOLA, C.J. As Agroindústrias de Carne do Sul do Brasil. Tese de doutorado. São Paulo: F.F.L.C.H./USP, 2002.

ESPÍNDOLA, C.J. As Agroindústrias no Brasil: o caso Sadia. Chapecó: Grifos, 1999.

FIGUEIREDO, E. Entrevista concedida à Revista Avicultura Industrial $\mathbf{n}^{\mathbf{0}}$ 6, ano 93, ed. 1102. São Paulo: Gessulli, 2002.

FIORENTIN, Laurimar. Entendendo a questão dos antibióticos promotores do crescimento em frangos. In: Avicultura Industrial $\mathbf{n}^{0}$ 8. São Paulo: Gessulli, 2005.

FREEMAN, C. Formal Scientific and Technical Institutions in the National Systems of Innovation. Brigthon: Science Policy Research unit, University of Sussex, 1988.

GIULIETTI, N. et al. Avicultura no Brasil, 1970-78: contribuição para um programa de desenvolvimento. Agricultura em São Paulo. São Paulo: IEA, 1981.

GONÇALVES, José S. A agricultura sob a égide do capital financeiro: passo rumo ao aprofundamento do desenvolvimento dos agronegócios. In: Informações Econômicas, V.35, n ${ }^{\circ}$. São Paulo, 2005.

HUNTON, Peter. 100 anos de genética avícola. In: Avicultura Industrial no 8 ed. 1148. São Paulo: Gessulli, 2006.

KIM LINSU. Da imitação à inovação: a dinâmica do aprendizado tecnológico da Coréia. Campinas: Ed. UNICAMP, 2005. 
ESPÍNDOLA, C.J. Trajetórias do progresso técnico na cadeia produtiva de ... LIMA, Eduardo A. et al. A Bioseguridade exigida em granjas de avós e matrizes. In: Avicultura Industrial. São Paulo: Gessulli, $\mathrm{n}^{\circ}$ $8,2005$.

MAMIGONIAN, Armen. Tecnologia e Desenvolvimento Desigual no Centro do Sistema Capitalista. In: Revista do Centro de Ciências Humanas, $\mathbf{n}^{0}$ 2. Florianópolis: CCH/UFSC, 1982.

MARQUES, H. L. Fase a fase. In: Avicultura Industrial $\mathbf{n}^{\mathbf{0}} \mathbf{1 0 .}$ São Paulo: Gessulli, 2002.

MARQUES, H. L. Protegida antes do nascimento. In: Avicultura Industrial nº 06. São Paulo: Gessulli, 2004.

MOHALLEM, José F.N. Linhagens exclusivas para o mercado nacional. In: Guia Gessulli da Avicultura Industrial $\mathbf{n}^{\mathbf{0}}$ 07, ano 94, Ed. 114. São Paulo: Gessulli, 2003.

PEREZ, C. \& SOETE, L. Catching up in technology: entry barries and windows of opportunity, In DOSI, G. et al (Org.). Techinical change and economic theory. Londres: Printer, 1988.

PHELPS, P. et al. In: Words Poutry Science Journal, v. 59, 2003.

PINAZZA, L.A. \& ALIMANDRO, R. Reestruturação no agribusiness brasileiro. Rio de Janeiro: ABAG, 1999.

RANGEL, I. M. A questão agrária brasileira. In: Questão agrária, industrialização e crise urbana no Brasil. SILVA, J.G. (Org.). Porto Alegre: UFRGS, 2000.

RANGEL, I. M. Ciclo, Tecnologia e Crescimento. Rio de Janeiro: Civilização Brasileira, 1982. 
ESPÍNDOLA, C.J. Trajetórias do progresso técnico na cadeia produtiva de ... RIZZI, Aldair T. Mudanças tecnológicas e reestruturação da indústria alimentar: o caso da indústria de frangos no Brasil. Tese de doutorado. Campinas: UNICAMP, 1993.

ROSEMBERG, N. Por dentro da caixa preta: tecnologia e economia. Campinas: Ed. UNICAMP, 2006.

SCHMIDT, Gilberto S. Competência Nacional. In: Avicultura, Suinocultura e Industrialização de carnes - Anuário. São Paulo: Gessulli, 1991.

SORJ, B. et al. Camponeses e Agroindústria. Rio de Janeiro: Zahar, 1982.

$<$ www.conab.gov.br> . Acesso em: 20 maio 2008.

Recebido em agosto de 2011 Aceito em setembro de 2011 